\title{
A RODOVIA WASHINGTON LUÍS E AS TRANSFORMAÇÕES NO ESPAÇO DE DUQUE DE CAXIAS
}

\author{
Artur Costa Lopes \\ Mestrando em etnomusicologia PPGM-UFRJ \\ Lopes1958@hotmail.com
}

\section{RESUMO}

Este trabalho visa apresentar algumas transformações surgidas com a construção da Rodovia Washington Luís (trecho da BR 040), que corta grande parte de bairros periféricos de Duque de Caxias, bem como a interação da população do entorno, com essas mudanças.

Através da análise de reportagens de jornais do ano de 1950 (inauguração da rodovia) e de 2013, baseado nos escritos de Henri Lefebvre, junto com entrevistas de moradores locais, estão sendo estudados o espaço social e físico dessa região, bem como a mesma está atualmente.

PALAVRAS-CHAVE: Rodovia Washington Luís. Mídia. Espaço. sociologia.

\begin{abstract}
This paper presents some transformations that have arisen with the construction of Washington Luis highway (the BR 040), which cuts most of the suburbs of Duque de Caxias, as well as the interaction of the surrounding population, with those changes.

Through analysis of newspaper reports of the year 1950 (inauguration of the highway) and 2013, based on the writings of Henri Lefebvre, along with interviews of local residents are being studied social and physical space in this region, and the same is currently.
\end{abstract}

KEYWORDS: Washington Luís Highway. Media. Space. sociology. 


\section{INTRODUÇÃO}

Nos dias de hoje o papel das rodovias é um dos assuntos que, por vezes aparece na pauta de discussões acadêmicas, no Brasil, tal como suas privatizações, estatísticas de acidentes, arrecadações, entre outros aspectos da vida cotidiana mais imediatista.

Algumas rodovias de maior porte, por demais utilizadas, vão se modificando ao longo dos anos e com isso seus arredores (sociedade em torno, e paisagem geográfica) acabam acompanhando esse processo, porém, com ritmos próprios, o que pode acarretar diferentes consequências, dependendo do contexto analisado.

Através de pesquisas, ainda na graduação, em 2008, comecei a observar que os textos que abordavam essa temática, normalmente possuíam uma leitura mais técnica e econômica, com pouca crítica às transformações e o que isso poderia gerar para a sociedade do entorno. Desse modo perguntei-me: como pode uma via de acesso da importância da rodovia Washington Luís, ou mesmo outra, não possuir um estudo aprofundado revelando sua trajetória e relevância para o Rio de Janeiro?

Como a inauguração da Rodovia Washington Luís perpassa o período de vigência do Estado Novo é importante observar que existe uma mudança maior na mentalidade da população daquela época, e esse fato ocorre em várias vertentes, pois, de qualquer maneira, modificando-se o tipo de governo (não-democrático) muda-se também o ideário do povo. Contudo, sempre com a influência da mídia, que possuía em meados do século $X X$, o rádio e os jornais (periódicos) como suas principais vias de comunicação direta com a população.

Como essa rota faz parte da vida diária de milhares de pessoas, a relevância principal dessa pesquisa diz respeito ao retorno que essa discussão pode trazer para os moradores, ou pesquisadores da mesma área, tanto no sentido de relações de pertencimento e de memória quanto no que podem contribuir para uma ampliação da noção de como esse espaço foi e está sendo ocupado. 


\section{A BUSCA DA MEMORIA SEM SER MEMORIALISTA}

O referencial teórico principal dessa pesquisa se baseia nos escritos de Henri Lefebvre, para discutir o conceito de espaço e a hipótese da urbanização completa da sociedade substituindo o campo, procurando desenvolver as seguintes questões como: quem produz e para quem? O que é produzir? $\mathrm{E}$ como e por que produzir?

Aliado a esse autor, outros dois são fundamentais para compreender como a sociedade atual (chamada de pós-moderna) encara essas transformações e demonstra suas relações de pertencimento com a rodovia analisada. Esses são Carlo Guinzburg (1987) e Stuart Hall (1997).

O objetivo do estudo, ainda em andamento, é explorar um tema, que contém pouquíssimo material disponível para pesquisa, por isso é tão desconhecido da maioria da população caxiense, buscando analisar como foi transmitida, através da mídia impressa, a notícia da inauguração para a população tal como essas transformações no espaço foram analisadas por moradores do entorno.

Portanto a memória da rodovia é um dos temas principais nessa pesquisa, entretanto, ela procura ser dinâmica, assim como as transformações ocorridas com a rodovia nos últimos anos, e, através da observação e de depoimentos de moradores do entorno, tenta entender como essas modificações ocorrem no plano micro e macro.

Sua metodologia se baseia na análise do material produzido pela mídia na época da inauguração. Entretanto, para haver um contraponto às noticias desses diferentes meios de comunicação, como já dito, estão sendo realizadas entrevistas com moradores mais antigos que ainda moram em bairros situados nas margens da rodovia. Para tal utilizamos a história oral retratando experiências vividas por pessoas que vivenciaram o mesmo momento, porém, possuíam outras visões. 


\section{BREVE HISTÓRICO DA RODOVIA}

A cidade de Duque de Caxias, mesmo antes de sua emancipação, no ano de 1943, recebe uma leva de emigrantes, em sua maioria nordestinos, que começam a aumentar demografia da cidade, dessa forma, a necessidade de meios de transporte de massa se inicia, visto que a substituição do trem pelos automóveis estava sendo mais intensa, devido, principalmente a chegada de produtos importados, que tiveram grande impulso com JK e, posteriormente, com os presidentes militares na década de 70 (GIANBIAGI; VILLELA, 2005).

Nesse contexto nasce uma variante (uma espécie de desvio por um caminho mais reto e largo) da estrada Rio Petrópolis, essa última que já era conhecida dos moradores da região desde 1928, quando foi inaugurada pelo então presidente Washington Luís, que tinha como lema principal: "Governar é abrir estradas" (DEBES, 2001). Entretanto, os anos 40 e 50 trouxeram um maior dinamismo para as estradas brasileiras, devido ao incentivo dado ao petróleo e ao caráter nacionalista e centralizador de ligar as cidades do Brasil por Getúlio Vargas, tendo continuidade nos governos seguintes (GOMES, 1988). Essa variante acaba se tornando o principal meio de ligação entre a Avenida Brasil e a serra de Petrópolis, além da Rio-Teresópolis, até a década de 90 quando surgem outros entroncamentos rodoviários como a Rodovia Presidente João Goulart (linha Vermelha).

Um resquício que ainda temos do nome "variante" é a linha de ônibus "periquitos $\mathrm{x}$ variante" que nada mais é do que um coletivo que passava por essa rota, assim como muitos outros que estavam surgindo, principalmente nos anos posteriores a década de 60 , que levavam as pessoas do centro a localidades periféricas que estavam começando a ser loteadas.

Porém, essa rodovia, apesar de ser criada com o principal intuito de desviar um caminho e encurtar o tempo de viajem da capital até a serra, acabou trazendo uma movimentação bastante considerável para a economia de Duque de Caxias, pois, às suas margens instalaram-se empresas que hoje podem ser consideradas o principal motor para a economia da Baixada Fluminense. 
Dentre elas pode-se citar a REDUC (com diversas unidades ligadas a derivados de petróleo e produtos químicos), fundada ainda na década de 60 e, posteriormente, o Pólo gás-químico. Além dessas, se instaurou um pólo moveleiro, sem contar com os feirões de malhas, transportadoras, o parque gráfico do jornal O Globo, o Caxias Shopping e três casas de shows de médio porte que mostraram uma nova visibilidade à rodovia e seu entorno. Contudo, esse "desenvolvimento" também trouxe consequências prejudiciais para a população do entorno, principalmente no que diz respeito à questão ambiental, onde não se pode deixar de citar o aterro sanitário de Gramacho. Esse, que foi desativado no ano de 2012, estava situado entre a baía de Guanabara e a rodovia, fato que facilitou durante muito tempo para que a cidade recebesse 0 lixo de quase toda a baixada fluminense e do município do RJ (SOUZA, 2002).

\section{A MODIFICAÇÃO DO ESPAÇO URBANO}

Segundo Febvre existem inúmeros conceitos para a palavra espaço, onde se podem destacar os espaços físico, mental e social (LEFEBVRE, 2006), portanto, pode ser entendido de várias maneiras, dependendo do ponto de vista e do contexto que for analisado. No caso desse trabalho, será recorrente o discurso de que a produção do espaço não implica numa leitura ortodoxa da produção-circulação-consumo, ou mesmo da espacialização do valor. O conceito possui um sentido histórico e sócio-cultural por conter uma dimensão temporal, subsumindo a historicidade do conceito de trabalho e uma dimensão espacial definida no momento da objetivação do trabalho concreto e do trabalho abstrato (GODOY, 2008).

A partir do estudo de uma rodovia e as transformações de seu entorno, esse conceito de produção do espaço é bastante pertinente, pois destaca a intercessão entre o trabalho concreto e o abstrato, ou seja, a produção de produtos se torna impessoal enquanto a produção de obras não se compreende se ela não depende de sujeitos (FEBVERE, 2006).

Portanto, o espaço será aqui entendido, não apenas do ponto de vista puramente geográfico, mas histórico, cultural e sociológico, visto que a metodologia de análise desse trabalho prioriza abordar um contexto geral (sem 
a pretensão de esvaziar o assunto), valorizando o espaço físico e social, mesmo se tratando de um recorte micro. Pois, de acordo com Hall (1997), a mudança de pensamento do sujeito moderno para o pós-moderno começa a destruir as barreiras das classes sociais, no que diz respeito ao sistema de informações, contudo, a recepção das mesmas, não possui uma contra resposta dos públicos diferentes.

\section{A INAUGURAÇÃO E O PAPEL DA MÍDIA}

As fontes utilizadas para a inauguração da rodovia são oriundas de periódicos da década citada, como Jornal do Brasil, A noite, Correio da Manhã e Gazeta de notícias, além da revista do Ministério dos transportes intitulada Rodovia, que apresentou bastantes detalhes técnicos sobre o tema.

$\mathrm{Na}$ década de 1940, grande parte dos acontecimentos importantes no Brasil tinha como pano de fundo o Estado Novo, assim como sua posterior decadência. Portanto, as notícias aqui relatadas devem ser observadas de maneira cuidadosa, visto que havia uma forte censura nos meios de comunicação independentes, com uma particularidade na revista Rodovia que é fruto do próprio governo. Esta representa bastante os interesses do Estado Novo, pois é parte do projeto de Vargas.

Mesmo que o período analisado seja a década de 50 a revista ainda possuía essas características e os jornais, pelo que foi analisado seguiram a mesma linha de pensamento, por isso, em seus escritos, sempre aparece uma forma de enaltecer a figura do "líder do povo", mesmo que de forma implícita ${ }^{1}$.

\footnotetext{
Precisamente as 9 horas de 6 de janeiro corrente, o general Eurico Gaspar Dutra, Presidente da República acompanhado pelo ministro José Pereira Lira e Sr. Carlos Alberto de Aguiar Moreira chegou a ponte sôbre o rio Meriti, interceptada pela fita simbólica auriverde e antes da qual se encontrava o monólito com a placa alusiva à inauguração da variante Rio-Petrópolis (Revista Rodovia. Dezembro. 1950, p. 7)
}

\footnotetext{
${ }^{1}$ Com o fim do Estado Novo a face da revista foi se modificando, acompanhando os sucessivos ministros dos transportes de então, enalteceu uma linguagem culta e de maneira que engrandecesse o governo com suas obras públicas.
} 


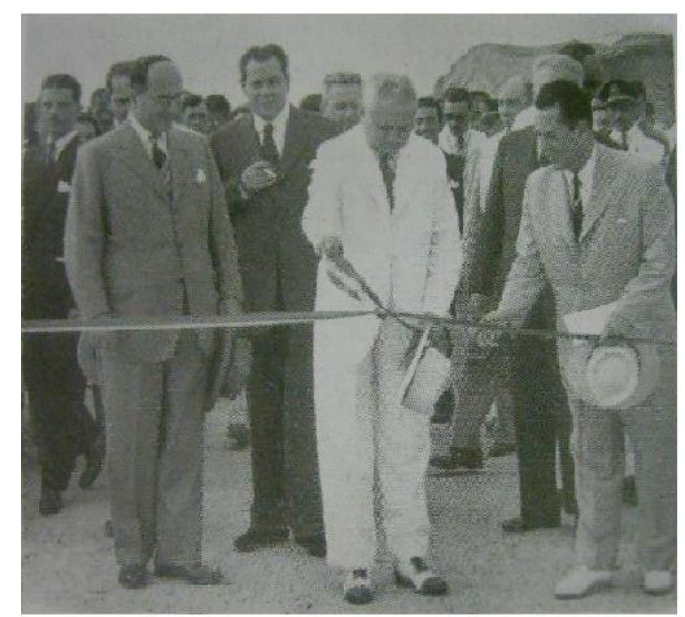

Fonte: Revista Rodovia. Janeiro de 1950. N. 119. p. 9.

Um dos objetivos da construção dessa nova via de acesso era de tornar mais rápido e curto o trajeto da então capital da república para Petrópolis, ou, conseqüentemente, para a região de Minas Gerais. Porém, a intenção do governo de demonstrar sua "magnitude e grandiosidade" para com as obras públicas, ficou bem clara nos escritos da revista. Por isso, ela não deixa de apresentar que a "Nova Rio-Petrópolis" possuía uma estrutura totalmente moderna para a época, se relacionarmos com outras estradas de rodagem brasileiras dos anos 50, pois, no mesmo ano da inauguração dessa rodovia, outras também surgiram com as mesmas características, onde a mais marcante (ainda desse ano) é a rodovia Presidente Dutra, que surge em 15 de julho com o trecho inicial de Parada de Lucas no distrito Federal a Garganta de Viúva da Graça no estado do Rio de Janeiro, compondo, então um trecho de 46 km, pavimentados e prontos para a utilização (Revista Rodovia Junho/ Julho 1950. p. desconfigurada).

As extensões territoriais são explicitadas na revista Rodovia como vemos abaixo:

A variante da Rio-Petrópolis (trecho da BR 3, Rio-Belo Horizonte) encontra-se a direita da Avenida Brasil, a 17 km da Praça Mauá, no Rio de Janeiro. Sua extensão é de $13 \mathrm{~km}$, entre a Avenida Brasil e Pilar, localidade onde alcança a antiga estrada. Em relação ao percurso anterior,, que tem $17 \mathrm{~km}$, o encurtamento geométrico é de 4 $\mathrm{km}$, sendo o virtual consideravelmente maior (Revista Rodovia Janeiro. 1950, p. 7.). 


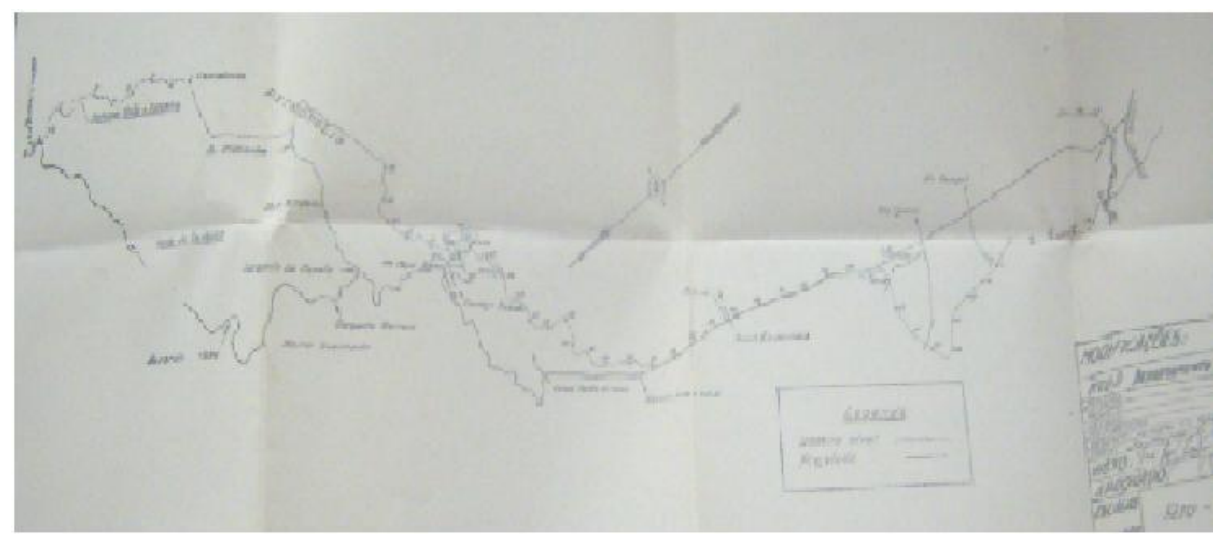

Fonte: Boletim do departamento Nacional de Estradas de Rodagem. 1950. n. 8. p. 15

Por conta, principalmente, da velocidade e trânsito menos intenso, essa estrada foi suprimindo a antiga Rio-Petrópolis. Apesar de ser uma rota interestadual, ela beneficiou demais os moradores de Duque de Caxias que habitavam regiões periféricas e bairros que começavam a ser loteados e, portanto, começavam a causar um inchaço na atual Presidente Kennedy.

O jornal correio da manhã destacou, em sua segunda página, a seguinte notícia:

\begin{abstract}
Pelo presidente da República será Hoje às 9 horas inaugurada a variante da estrada Rio Petrópolis, que partindo da Avenida Brasil, vai até Pilar, no Estado do Rio, numa extensão de 13 quilômetros, encurtando o caminho para Petrópolis de quatro quilômetros. A nova variante evitará a passagem por Caxias, sendo grande o seu afastamento dessa cidade fluminense, onde de agora em diante 0 tráfego ficará muito desafogado, e também num trecho de $17 \mathrm{~km}$ de estrada velha para Petrópolis, pois só no fim desse trecho é que vai ter a nova variante (Correio da Manhã, 6 de Janeiro de 1950 p. 2).
\end{abstract}

A inauguração Variante da Rio-Petrópolis foi um acontecimento importante a nível estadual e nacional, pois, fazia parte de uma transformação e renovação, assim como ocorrido em outros locais do país no que diz respeito à modernidade de construção de estradas de rodagem. Também por estar presente no então Estado da Guanabara ao lado da capital federal, pois vale lembrar que Brasília só se constitui como tal nos anos 60 .

Por isso sua inauguração foi tão pomposa, tendo, inclusive, a participação do Presidente da República e de outras figuras importantes da política nacional. Todavia, assim como a transferência da capital para o 
Brasil traria sérios rombos nos cofres públicos essa, como outras rodovias criadas na época, não foram diferentes, como é visto nos escritos abaixo:

Após o hino nacional, o General-Presidente Eurico Dutra descobriu a placa comemorativa e, descerrando o laço que detinha o tráfego na ponte sobre o rio Meriti, entregou ao uso público a variante da RioPetrópolis, com $13 \mathrm{~km}$ de extensão, cujo custo se elevou a cerca de 60 milhões de cruzeiros (Revista Rodovia dezembro, 1950, número 119, p. 7).

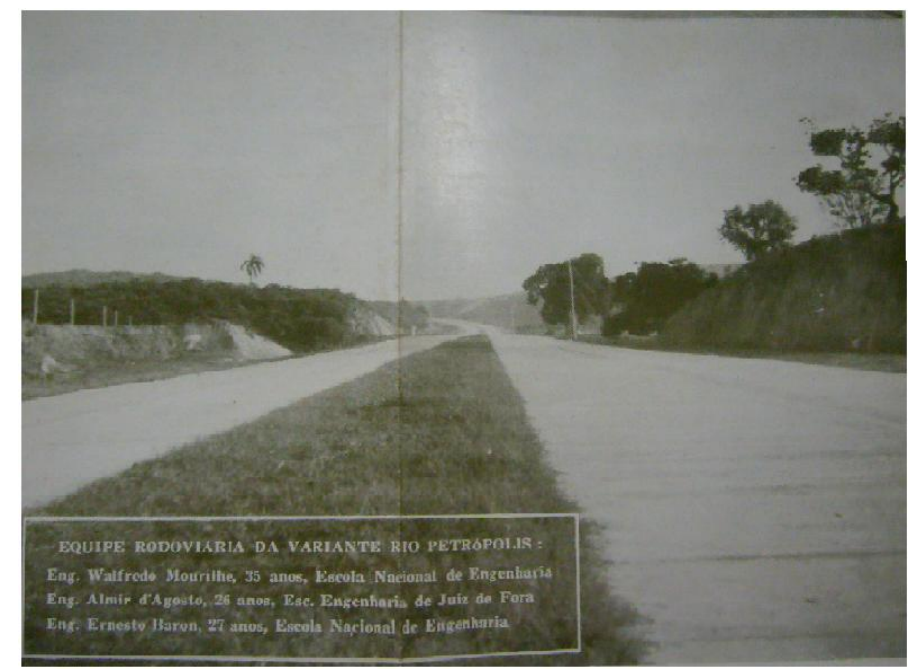

Fonte: Revista Rodovia. Janeiro de 1950. N. 119. p.8

Essa rodovia surgiu no período vigente de Eurico Gaspar Dutra, como mostra as notas dos periódicos. Esse governo foi caracterizado por uma redução da intervenção do Estado na economia, o aperfeiçoamento da assistência estatal nos setores de saúde, alimentação, transporte e energia, a adoção de uma política econômica liberalizante, de forma a facilitar o acúmulo de capital às custas de baixos salários e a expansão das empresas estrangeiras" (BASTOS, 2001). Essa "oposição" ideológica e prática ao Estado Novo de Vargas havia sido adequada à burguesia para uma acumulação primitiva de capital. Depois disso, já fortalecida, o Estado tornou-se um obstáculo, e a burguesia passou a querer participar mais de perto nas decisões governamentais (BASTOS, 2001).

Portanto, Abriram-se as portas da economia brasileira a inúmeras importações norte-americana sendo, conseqüentemente, a moeda de então, o Cruzeiro, desvalorizada, para tentar evitar o crescimento excessivo das importações. Nesse contexto, a nova Rio-Petrópolis trouxe para a cidade de 
Duque de Caxias uma maior visibilidade, que já podia ser observada com a implementação da antiga Rio-Petrópolis, porém em um grau muito menor. Entretanto, como afirma Febvre, o capitalismo conseguiu atenuar (sem resolver) durante um século as suas contradições internas, porém, como 0 mesmo autor indaga, qual o preço disso? Não há números que exprimam. Por que meios? Isso, sabemo-lo nós: ocupando o espaço, produzindo um espaço (FEBVRE, 1973).

Dessa forma, a população ainda "paga" o preço de uma ocupação do espaço planejada apenas por um lado da sociedade, que nesse caso era uma elite política e industrial que observava, nessa área uma grande alternativa de alojar indústrias e estender bairros através da venda de loteamentos. Fato que resultou em verdadeiros crimes ambientais e contra a saúde pública, pois, numa parte dessa rodovia existem indústrias altamente tóxicas que provocam danos lentos, porém significativamente cruéis, à população do entorno (SOUZA, 2002).

Esse fato é lembrado pelo senhor Rômulo quando afirma que "embora rodovia traga desenvolvimento econômico para o município o impacto ambiental é muito grande"2.

A gazeta de notícias de 7 de janeiro foi o jornal que dedicou mais páginas ao assunto. Já na capa ele destaca com a chamada "Inaugurada a variante Rio-Petrópolis" e segue com um subtítulo dizendo que "Trará economia de percurso entre a capital federal e a cidade serrana". Essas duas frases resumem muito bem a intenção do jornal em retratar de forma positiva a nova rodovia, principalmente no que diz respeito à redução do tempo entre os moradores da antiga capital federal (RJ) e a cidade imperial. O periódico ainda discorre sobre os dados técnicos e inovadores da variante dando ênfase ao dezafogamento do trânsito que, como diz o jornal, estava pesadíssimo, pois, servia de acesso à

Petrópolis, a atual estrada de Teresópolis, à União Indústria, à RioBahia em futuro próximo, à nova rodovia Rio-Belo Horizonte, à rodovia Niterói-Campos-Vitória-Feira de Santana, e à nova Teresópolis-Friburgo que deverá ser construída.(Gazeta de notícias.1950. 7 de janeiro. Pg. 1)

\footnotetext{
${ }^{2}$ Depoimento fornecido por Rômulo Muniz França em 10 de maio de 2014
} 
O periódico ainda mostra os gastos empreendidos pela construção da rodovia, entretanto, contrapõe, apresentando os benefícios econômicos que trarão para o motorista nessa nova rota.

O custo da variante Rio-Petrópolis atingiu cerca de 60 milhões de cruzeiros (...) a coletividade será beneficiada com uma economia, únicamente em combustível, de cerca de 4 milhões de cruzeiros por ano, resultante do encurtamento de $4 \mathrm{~km}$ sobre o ântigo percurso, sem considerar a melhoria das condições técnicas. A economia em tempo é estimada em 350.000 horas anuais. (Gazeta de notícias. 1950. 7 de janeiro. Pg.14)

A reportagem do jornal A Noite de 7 de janeiro de 1950 assim como o correio da manhã (pois esse segundo também noticiou essas palavras) engloba a inauguração dessa rodovia a outros feitos do governo no resto do Brasil, dando ênfase para uma rota muito utilizada atualmente, que é a RioBahia.

\begin{abstract}
A inauguração da nova variante da Rio-Petrópolis não mostra apenas o interesse do governo pela abertura de novas vias de comunicação, como exige o teor de uma política rodoviária das mais adiantadas. Mas deve significar que não se restringe ao Rio e arredores o desejo de abrir estradas. No note e no centro-sul a dinâmica rodoviária está em plena ebulição. A Rio-Bahia, ainda agora percorrida de automóvel pelo Sr. Juraci Magalhães, que viajou para Salvador em poucos dias, e também batida, de Recife ao Rio em pouco mais de 48 horas, por um comerciante de Pernambuco. A estrada General Dutra, que unirá o Rio a São Paulo em 8 horas; a ligação com Mato grosso a cargo de batalhões do exército; as estradas que no norte ligam vários estados; a trans-brasiliana que tornará possível, dentro de algum tempo a viajem Belém-Rio. Tudo isso está em plena execução e algumas já concluídas numa síntese de atividades administrativas nesse setor ( $A$ Noite. 1950.7 de janeiro. Pg 4).
\end{abstract}

A manipulação feita pela mídia foi bastante eficaz em favor do governo, que mesmo se apresentando democrático, poderia possuir forte influência sobre os meios de comunicação, tendo em vista o cunho das reportagens, ou, de acordo com outra análise, encarou o fato como mera formalidade sem querer destacar alguma crítica ao acontecimento.

Dessa maneira, o papel do homem na construção do espaço é fundamental, porém, não apenas na construção, mas na re-construção 
(transformações). Entretanto, os meios de comunicação (destacando os da década de 50 de mídia impressa) não deram essa valorização, enaltecendo outros aspectos como símbolos, grandes personagens e termos puramente técnicos, o que Febvre chama de espaços matemáticos (FEBVRE, 2006).

De acordo com as notícias, é importante destacar que outra questão debatida sobre as décadas de 40 e 50 dizem respeito ao conceito de modernidade, pois, com o fim da Segunda Guerra ${ }^{3}$, começou a haver um novo tipo de pensamento sobre esse conceito. Intelectuais do Instituto Superior de Estudos Brasileiros - ISEB - por exemplo, planejam um novo tipo de projeto desenvolvimentista para o Brasil, onde o industrialismo, o ensino tecnicista, a abertura gradual para o mercado externo e o rodoviarismo ganhariam um lugar de destaque nos planos do governo (HOBSBAWM , 2002. p. 259). Sendo que esse último fator se apresenta com bastante intensidade no Brasil e em muitos países considerados "subdesenvolvidos" por conta, principalmente, do incentivo a utilização de derivados do petróleo como combustíveis para os novos automóveis caminhões e ônibus que começavam a fazer parte da rotina dessas sociedades (HOBSBAWM , 2002. p. 259). Com relação aos projetos rodoviários, observamos uma espécie de elo com o governo Washington Luís, pois, apesar de no governo Vargas, terem desenvolvido inúmeras estradas de rodagem, o impulso foi muito maior nos governos que o precederam, como $o$ de Dutra e, principalmente, os de Juscelino e dos militares a partir de 1970.

Um exemplo concreto desse incentivo fiscal ao rodoviarismo como elemento de modernidade foi a instalação da empresa alemã Volkswagen, que construiu fábricas em diversos países da África e América, nos anos 1960, completando um processo transnacional de manufatura em que vivia o mundo ocidental em tempos de Guerra Fria (HOBSBAWM, 2002).

O jornal do Brasil se antecipa ao fato da inauguração, realizando uma entrevista com o presidente do D.N.E.R. - Saturnino Braga - no dia 6 de Janeiro do mesmo ano (dia da inauguração). Nessa reportagem, Saturnino destaca as melhorias realizadas pelo governo, no que diz respeito às novas malhas rodoviárias construídas no Brasil, ligando o país de Norte a Sul (Jornal

\footnotetext{
${ }^{3}$ Vale lembrar que esse acontecimento culmina, no Brasil, com o término do período de governo de Getulio Vargas.
} 
do Brasil, 6 de janeiro de 1950), como visto na reportagem acima do jornal A Noite .

Em suma, os periódicos não apresentaram críticas negativas a construção da rodovia, pelo contrário, enalteceram bastante a obra e deram bastante significado a ela, fato que, segundo a visão marxista de Febvre, reforça a diferença de classes e a questão do operário e dos moradores do entorno ${ }^{4}$ (de extrema importância) e que, nesse caso não foi valorizada.

Por conta disso esse trabalho visa, em sua fase posterior, apresentar outras visões, (a dos moradores do entorno), para não se restringir a uma observação elitizada sobre o assunto e para apresentar questões do cotidiano local, tal como as relações de pertencimento dos moradores com seu entorno (GINZBURG, 1987). Além disso, as relações espaciais são geradas logicamente, mas tornam-se dialeticizadas através da atividade humana no espaço e sobre ele (SMITH, 1998). Sendo assim, esse espaço de dialética e de conflito que produz a reprodução, introduzindo nele suas múltiplas contradições (SMITH, 1988). De acordo com essa linha de pensamento, não há como analisar um espaço por si só, é necessário um contexto mais amplo, mesmo que seja local. Mas como essa outra fase (de entrevistas) já foi iniciada, será apresentado na pesquisa dois relatos importantes, o da Senhora Elza (Elza Portela) e do Senhor João (João Dias).

De acordo com a Senhora Elza, (moradora do entorno no antes da construção da rodovia) antes mesmo da inauguração da rodovia já existia um tráfego considerável na pista, essa que era composta - pré-variante RioPetrópolis - apenas pela pista de descida ${ }^{5}$. Ou seja, se compararmos aos dias de hoje, teríamos antes dos anos 50, no local da nova Rio-Petrópolis, apenas uma via de mão dupla que ligava Petrópolis a Avenida Brasil.

Nessa estrada trafegavam tipos diferentes de meios de transporte. Como se tratava de um período de transição política que mudaria os rumos do país (nos referimos a maior abertura ao capital externo feito por governos posteriores a Getúlio Vargas), se via nesse local um misto entre lotações ${ }^{6}$,

\footnotetext{
${ }^{4}$ Segundo a pesquisa realizada nenhum jornal, mesmo nos 10 dias seguintes apresentam a visão de algum morador local sobre a rodovia.

${ }^{5}$ Depoimento fornecido por Elza Ferreira Portela em 18 de agosto de 2008.

6 Havia em Caxias apenas dois tipos de coletivos que atuavam de maneira irregular. Esses, posteriormente, se tornariam "as atuais empresas de transporte coletivo da região". BRAZ. p. 36 - a
} 
carros de tração animal (carroças), gasogênios, eqüinos (muito comuns em Caxias até finais dos anos 50), automóveis, sem contar com a população que trafegava nas margens da rodovia caminhando.

No relato da Senhora Elza observa-se a dificuldade de conseguir se locomover nessa época.

Eu estudava no Rio, eu saía de casa 3 horas da manhã pra estudar no Rocha, na linha da Central, é ali o Méier (..) eu ia de trem até São Francisco Xavier, lá em soltava em triagem, pegava o bonde e ia pra escola (...) e pra vir pra casa eu pegava o bonde até o Méier, pegava o ônibus do Méier até a Penha, da Penha pegava o ônibus até Caxias, de Caxias eu ia a pé até a minha casa (Informação verbal) ${ }^{7}$.

Outro fato comum que se via na rodovia Washington Luiz, mesmo antes de sua inauguração (Segundo Dona Elza), era a mendicância que margeava sua pista. Como Duque de Caxias sempre teve uma desigualdade social de larga escala, era comum haver pedintes em vários pontos da cidade. De acordo com Dona Elza, via-se constantemente na beira da rodovia, em diferentes alturas, crianças pedindo.

Ao redor dela [da Variante Rio-Petrópolis] era pobreza (...) naquela época as crianças ficavam beirando aquela Washington Luiz (...) muitos motoristas jogavam alguma coisa pela janela, nem chegavam a parar (...) você via muita pobreza, muita tristeza beirando aquela Washington Luiz (Informação verbal) $)^{8}$

Isso ocorria na rodovia, pois nela trafegavam inúmeras pessoas de diferentes classes sociais e, consequentemente, os que possuíam carros do ano, com um status social elevado, visto que o automóvel, naquela época, era um artigo de luxo. Portanto, o que ocorria era muito parecido com o que hoje temos na BR 116 e na BR 101, na altura de Feira de Santana e Teixeira de Freitas, ou mesmo em outras imediações, onde além da venda de mercadorias - muita das vezes peças indígenas, frutas e derivados da

primeira "linha" de lotações da cidade pertencia ao Sr. José Cardoso Bessa e servia ao Parque Lafaiete. As mais poderosas empresas de transporte coletivo União e Reginas, surgiram respectivamente, na linha Centro-Itatiaia (União) e como viação Periquitos (Reginas), com apenas um veículo onde Odilon Pereira Teixeira, atual proprietário, trabalhava como cobrador, num velho furgão dirigido pelo pai.

${ }^{7}$ Depoimento fornecido por Elza Ferreira Portela em 18 de agosto de 2008.

${ }^{8}$ Depoimento fornecido por Elza Ferreira Portela em 18 de agosto de 2008. 
mesma, como bananadas e goiabadas-, vê-se pessoas pedindo alimentos ou algumas moedas para as que transitam de passagem nesses locais, fato que apenas reforça o abismo social existente em diversas extremidades e épocas do território brasileiro, demonstrando assim como esse país mesmo sendo grande em extensão territorial possui laços que o une, nesse caso a pobreza e a riqueza convivendo lado a lado.

Esse fato, afirma os escritos a opção de Febvre para escolher uma abordagem de classes para trabalhar a questão da produção do espaço. Ou seja, diante da pergunta inicial - para quem produzir e quem produz - observase que a intervenção dos diferentes atores nesse contexto pode modificar o cenário a ponto de servir de referencia para um depoimento que foi recolhido 50 anos após o acontecido.

Portanto, o que se pode concluir, é um problema social que além de não ter sido resolvido, apenas mudou seu eixo, saindo de uma região mais observada pela imprensa e aparecendo em localidades onde o governo não possui uma assistência social que beneficie todos os moradores. Além disso, o homem atua sobre a natureza para atender as suas necessidades imediatas, modificando a sua própria relação com a natureza e com a sociedade. Entretanto, essas relações sociais não são uniformes nem no tempo e muito menos no espaço, depende da realidade contextual. Enfim, o homem reproduz, mas, também produz, neste aspecto, o espaço envolve as contradições e as particularidades do real, influenciando os processos sociais subseqüentes. (GODOY, 2008)

Como já dito, um dos principais objetivos dessa obra rodoviária foi a questão do encurtamento do tempo de trajeto, essa que em dados concretos podia ser avaliada, (para automóveis de época) em 15 minutos médios por veículos, ou seja, 10 para os carros e 20 para caminhões. E, como o Ministério dos Transportes visa, assim como a maioria dos órgãos governamentais, obter um apoio popular a partir de relatórios de censos, ele ainda divulgou que esses minutos poupados correspondiam anualmente a 350.000 horas anuais em relação ao tráfego atual (Revista Rodovia, janeiro de 1950. Pg. 2), apresentando ainda a economia realizada no combustível como nos relatos abaixo: 
Utilizando unicamente a mesma relação, a economia em combustível, derivada do encurtamento geométrico de $4 \mathrm{~km}$, e desprezando o encurtamento virtual resultante das muitas melhorias características técnicas, pode ser avaliado em 4.000.000,00 anuais (Revista Rodovia, janeiro 1950. Pg. 2)

Os acessos da nova via são os pontos que auxiliam que ela foi bastante benéfica para o melhoramento do tráfego local, visto que abriu mais caminhos para os já existentes.

Vale lembrar que, antes da inauguração, já havia ali um caminho, inclusive utilizado por moradores, como já visto nos relatos da Senhora Elza. Portanto, observamos que a variante foi constituída a partir da duplicação de uma estrada existente, ou seja, o local onde foi construída nova Rio-Petrópolis já era caminho para a passagem (em alguns trechos) de pessoas e mercadorias antes mesmo de sua inauguração propriamente dita.

\section{CONSIDERAÇÕES FINAIS}

Atualmente a rodovia Washington Luís apresenta mudanças significativas desde sua inauguração (62 anos atrás). Depois de sua privatização para a empresa Concer, que começou a valer em 1996, ela foi bastante iluminada e o asfalto recebeu melhor tratamento, além das passarelas e canteiros de cimento e suas pistas foram duplicadas, ou seja, ela possui quatro pistas centrais e duas pistas laterais em diversos trechos, o que facilita o trânsito ${ }^{9}$. Porém, sem desafogá-lo totalmente, principalmente pela manhã e ao final da tarde. Fato lembrado durante a entrevista com a Senhora Sônia ${ }^{10}$ que comenta que:

hoje já ocorrem engarrafamentos de 3 a $5 \mathrm{~km}$ entre as 6:00 e 9:00 horas da manhã e alguns a tarde, isso com todos esses duplicamentos que ocorreram ao longo dos anos, imagina se não tivesse? Mas, pelo visto terão que duplicar mais ${ }^{11}$

\footnotetext{
${ }^{9}$ Disponível em:

http://www.concer.com.br/portals/0/RelatorioAnual/2012/pdf/Relatorio\%20Anual_Site.pdf

${ }^{10}$ Entrevista realizada em 22/5/2013 com a senhora Sônia Maria Costa Lopes.

${ }^{11}$ Depoimento fornecido pela Senhora Sônia Maria Costa Lopes em 22 de maio de 2013.
} 
Portanto, observa-se que, apesar das rodovias exercerem um grande papel para o dinamismo dos transportes, ela não consegue sobreviver sozinha, por isso iniciativas como a de intensificar outros meios como hidroviários e ferroviários podem ser consideradas bastante louváveis, ainda mais com a quantidade de rios navegáveis que possuímos e com a malha ferroviária que foi desativada, seja para o turismo, transporte de mercadorias ou de passageiros.

Duque de Caxias é uma cidade em constante transformação no que diz respeito à infra-estrutura e à economia. No entanto, suas bases social e política mudaram apenas de personagens, mas progrediram (em favor da população como um todo) a passos bastante largos, como é perceptível nos dias de hoje. Portanto, como visto no período analisado e até os dias de hoje, observa-se o retrato atual da cidade: condições econômicas faraônicas, porém, essas não são bem repartidas entre a sociedade.

Para concretizar essa afirmação existem vários exemplos, como os pólos industriais que temos em diversas áreas da cidade, o faturamento mensal que geramos com o petróleo (principalmente com a refinaria), os impostos que a cidade arrecada, devido a sua densidade demográfica ser bastante intensa, e daí em diante.

Essas indústrias fazem parte da vida de muitos moradores do entorno da rodovia, aumentando os níveis de identidade com a mesma, fato que pode ser comprovado com o depoimento do senhor Rômulo ${ }^{12}$ que, além de trabalhar dentro da REDUC, comenta que "a duplicação da pista trouxe a instalação de empresas e melhorou o tráfego da região. Isso ocorre por conta do poder público investir no acesso a essas indústrias" ${ }^{13}$, principalmente para cargas pesadas e transporte para os operários, contudo, quando se adentra mais a fundo nos bairros próximos observa-se que a preocupação do Estado com os moradores não ocorre na mesma proporção.

Por fim, a relação do espaço com o habitante local, de acordo com o papel da mídia da época, é nula. Com isso, observa-se uma análise jornalística superficial e pouco investigativa e social, limitando-se à reescrever e interpretar de maneira pouco argumentativa os escritos da Revista Rodovia. Portanto, a

\footnotetext{
${ }^{12}$ Entrevista realizada com o senhor Rômulo Muniz França em 10/5/2014.

${ }^{13}$ Depoimento fornecido por Rômulo Muniz França em 10 de maio de 2014
} 
partir da análise dos jornais citados e do depoimento de Elza, vê-se que a rodovia foi uma melhoria para a população, visto que além de diminuir o tempo de trajeto, intermunicipal, beneficiou o acesso a regiões periféricas, valorizando-as, principalmente no que diz respeito à mobilidade urbana, porém, essa foi se deteriorando no decorrer das décadas por conta do aumento populacional de Duque de Caxias, que não teve um transporte público que suprisse a necessidade do deslocamento dessas pessoas.

Será então que a produção desse espaço realmente serviu aos anseios da população em todas assuas diferentes classes sociais? De que forma um novo trajeto, que trouxe consigo uma enorme especulação imobiliária, devido à valorização de bairros no entorno, foi benéfico para a população que ali já se encontrava e para os que foram se instalando?

\section{REFERÊNCIAS}

\section{Bibliografia}

BASTOS, Pedro Paulo Zahluth. O presidente desiludido: pêndulo de política econômica no governo Dutra (1946-1951). São Paulo. UNICAMP. 2001.

BRAZ, Antônio Augusto. Vidas em Transição: A Cidade e a Vida na Cidade em Duque de Caxias (RJ) nas Décadas de 30, 40 e 50 do Século XX. Vassouras: USS, 2006

Correio da Manhã, 6 de Janeiro de 1950 p. 2.

DEBES, Célio. Washington Luís: segunda parte (1925-1930), Imesp, São Paulo, 2001

GIAMBIAGI, F. ; VILLELA, A. et al. Economia Brasileira Contemporânea. Rio de Janeiro: Elsevier, 2005.

GINZBURG, Carlo. O queijo e os vermes: o cotidiano e as ideias de um moleiro perseguido pela inquisição. São Paulo. Companhia das Letras 1987.

GODOY, Paulo Roberto Teixeira de. A produção do espaço: uma reaproximação conceitual da perspectiva Lefebviriana. GEOUSP - Espaço e Tempo, São Paulo, № 23, 2008

GOMES, Angela de Castro. A invenção do trabalhismo. Rio de Janeiro. IUPERJ. 1988 
HALL, Stuart. A identidade cultural na pós-modernidade. Rio de Janeiro: DP\&A,1997.

HOBSBAWM, Eric J. Era Dos Extremos. Companhia das Letras. 2002. Pág 259.

LEFEBVRE, Henri. A produção do espaço. Trad. Doralice Barros Pereira e Sérgio Martins (do original: La production de l'espace. 4e éd. Paris: Éditions Anthropos, 2000). Primeira versão : início - fev.2006

- A Reprodução das Relações de Produção. Tradução: Antonio Ribeiro e M. do Amaral. Porto (Portugal): Publicações Escorpião Cadernos O Homem e a Sociedade, 1973.

SMITH, N. Desenvolvimento Desigual - natureza, capital e a produção do espaço. Tradução: Eduardo de Almeida Navarro. Rio de Janeiro: Bertrand. Brasil, 1988.

SOUZA, Marlucia Santos de. Escavando o passado da cidade (História política da Cidade de Duque de Caxias). Dissertação de Mestrado. Niterói: UFF, 2002.

\section{Periódicos}

NOVO, acesso a Petrópolis. Correio da Manhã, 6 de Janeiro de 1950 p. 2.

INAUGURADA, a variante Rio-Petrópolis. Gazeta de notícias 7 de janeiro. Pg 1 ;

MELHORIA. Gazeta de notícias 7 de janeiro. Pg 14;

ESTRADAS, e ferrovias. A noite de 7 de janeiro de 1950. Pg 4

O ENGENHEIRO, Saturnino Braga. Jornal do Brasil, 6 de janeiro de 1950.

\section{Entrevistas}

Entrevista realizada com a Elza Ferreira Portela em 18 de agosto de 2008.

Entrevista realizada com o senhor Rômulo Muniz França em 10 de maio de 2014.

Entrevista realizada com a senhora Sônia Maria Costa Lopes em 22 de maio de 2013 